\title{
AÇÃO COAGULANTE DO EXTRATO DE SEMENTES DE MORINGA PREPARADO EM DIFERENTES SUBSTÂNCIAS QUÍMICAS
}

Paola A.V. Lo Monaco ${ }^{1}$, Antonio T. de Matos $^{2}$, Valdeir E. Júnior ${ }^{3}$, Felipe S. Nascimento ${ }^{4}$, Ed Carlo R. Paiva ${ }^{5}$

\author{
RESUMO
}

Com a realização deste trabalho, teve-se como objetivo avaliar o efeito da adição de $\mathrm{NaCl}$ e de $\mathrm{Ca}(\mathrm{OH})_{2}$ no preparo do extrato de sementes de moringa (Moringa oleifera), quando utilizado na remoção de turbidez da água residuária de suinocultura. Foram realizados três tratamentos, no primeiro utilizou-se apenas o extrato de sementes de moringa; no segundo, apenas solução de $\mathrm{NaCl}$ ou $\mathrm{Ca}(\mathrm{OH})_{2}$, e no terceiro, o extrato de moringa preparado com $\mathrm{NaCl}$ ou $\mathrm{Ca}(\mathrm{OH})_{2}$. Equações matemáticas foram ajustadas, por regressão, relacionando-se a turbidez em função das alíquotas utilizadas em cada tratamento. De acordo com os resultados obtidos, pode-se concluir que a adição do extrato de sementes de moringa, preparados em água destilada ou solução $\mathrm{NaCl}$, não proporcionou remoção de turbidez da água residuária da suinocultura. Praticamente não houve diferença na remoção de turbidez da ARS entre os tratamentos que receberam o extrato de sementes de moringa e o extrato de sementes de moringa preparado em solução de $\mathrm{Ca}(\mathrm{OH})_{2}$. As maiores remoções de turbidez da ARS foram obtidas utilizando-se a alíquota de $32 \mathrm{~mL}$, o que equivale a $0,64 \mathrm{~g} \mathrm{~L}^{-1}$, tanto de solução $\mathrm{Ca}(\mathrm{OH})_{2}$ como de extrato de sementes de moringa preparado em solução $\mathrm{Ca}(\mathrm{OH})_{2}\left(0,64 \mathrm{~g} \mathrm{~L}^{-1}\right.$ de cal $+0,64 \mathrm{~g} \mathrm{~L}^{-1}$ de sementes de moringa), proporcionando, respectivamente, remoções de 97,4 e $97,5 \%$ na turbidez inicial.

Palavras-chave: água residuária de suinocultura, coagulação, turbidez.

\begin{abstract}
COAGULATING ACTION OF MORINGA SEED EXTRACT PREPARED USING DIFFERENT CHEMICALS

This study was done to evaluate the effect of $\mathrm{NaCl}$ and $\mathrm{Ca}(\mathrm{OH})_{2}$ for preparing moringa (Moringa oleifera) seed extract used for turbidity removal from swine wastewater. The treatments were seed extract alone, only $\mathrm{NaCl}$ or $\mathrm{Ca}(\mathrm{OH})_{2}$.and the seed extract prepared with $\mathrm{NaCl}$ or $\mathrm{Ca}(\mathrm{OH})_{2}$. Regression equations relating turbidity to the application rate were calculated. The data showed that the addition of moringa seed extract prepared in distilled water or $\mathrm{NaCl}$ solution, did not provide for turbidity removal from the wastewater. Practically, there was no difference in the turbidity removal between moringa seed extract and the extract prepared in $\mathrm{Ca}(\mathrm{OH})_{2}$, solution. The maximum turbidity reduction was obtained using $32 \mathrm{~mL},(=0.64$ $\left.\mathrm{g} \mathrm{L}^{-1}\right)$ of $\mathrm{Ca}(\mathrm{OH})_{2}$ solution or seed extract solution prepared in $\mathrm{Ca}(\mathrm{OH})_{2}\left(0.64 \mathrm{~g} \mathrm{~L}^{-1}\right.$ of lime $+0,64 \mathrm{~g} \mathrm{~L}^{-1}$ of moringa seeds), with respective removal of 97.4 and $97.5 \%$ of the initial turbidity.
\end{abstract}

Keywords: coagulation, swine wastewater, turbidity.

\footnotetext{
Recebido para publicação em 01/11/2011. Aprovado em 05/09/2012.

1- Engenheira Agrícola, Professora do Instituto Federal de Educação, Ciência e Tecnologia do Espírito Santo, Campus Centro Serrano, Santa Maria de Jetibá - ES, paolalomonaco2004@yahoo.com.br.

2- Engenheiro Agrícola, Professor Associado do Departamento de Engenharia Agrícola (DEA) da Universidade Federal de Viçosa (UFV), atmatos@ufv.br.

3- Engenheiro Agrícola e Ambiental, M.S em Engenharia Agrícola, Doutorando em Engenharia Agrícola, DEA/UFV, valdeir. junior@ufv.br.

4- Engenheiro Agrícola e Ambiental, Mestrando em Hidráulica e Saneamento na EESC-USP, felipskt@yahoo.com.br.

5- Engenheiro Civil. Professor Adjunto do curso de Engenharia Civil da Universidade Federal de Goiás, Campus Catalão, edcarlopaiva@yahoo.com.br.
} 


\section{INTRODUÇÃO}

A suinocultura moderna, caracterizada pelo confinamento de animais, gera grandes volumes de águas residuárias, com alto poder poluente. Quando essas águas residuárias são dispostas no meio ambiente, sem tratamento, podem causar grandes problemas ambientais, tais como degradação ou destruição da flora e da fauna, além de comprometer a qualidade da água e do solo (MATOS et al. 2006).

Comonalegislaçãoambientalestãoestabelecidos padrões para lançamento de efluentes em corpos hídricos, torna-se necessário, caso a opção seja esta forma de destinação final, que sejam desenvolvidas técnicas de minimização e tratamento final dos resíduos gerados (LO MONACO et al., 2009; DAL BOSCO, et al., 2008), o que demanda a utilização de sistemas muito bem dimensionados e operados.

O sulfato de alumínio destaca-se como o coagulante químico mais utilizado no Brasil, no tratamento de água a ser distribuída à população, pela alta eficiência na remoção de sólidos em suspensão e pelo relativo baixo custo. No entanto, esse sal torna-se caro para áreas mais afastadas em função do custo do seu transporte, além de poder ocasionar problemas de saúde, em decorrência do alumínio residual nas águas tratadas e dificultar a disposição final do lodo produzido nas estações de tratamento. Além disso, a utilização de sais de alumínio apresenta outras desvantagens tais como produção de grande volume de lodo, consumo da alcalinidade do meio, acarretando custos adicionais com produtos químicos utilizados na correção do pH (SILVA et al., 2007).

A utilização de coagulantes naturais, produzido no local e com baixo custo financeiro, pode proporcionar atenuação nos problemas ligados ao consumo de água não potável e despejos de águas residuárias, sem tratamento, em corpos hídricos receptores. Além disso, de acordo com Moraes (2004), os coagulantes/floculantes naturais têm demonstrado vantagens em relação aos químicos, especificamente em relação à biodegradabilidade, baixa toxicidade e baixo índice de produção de lodos residuais.

Muitos são os resultados de pesquisas comprovando a eficiência do extrato de sementes de moringa (Moringa oleifera), na remoção de turbidez (ABDULSALAM et al., 2007; MATOS et al., 2007a; LO MONACO et al., 2010), sólidos suspensos (BHATIA et al., 2007), surfactantes aniônicos (HEREDIA; MARTIN, 2009), corantes (HEREDIA et al., 2009), óleos e graxas (CHAGAS et al., 2009), Demanda Química de Oxigênio (BHATIA et al., 2007; CHAGAS et al., 2009) e até microrganismos (MUYIBI; EVISION, 1995; SILVA et al., 2007; LO MONACO et al., 2010), de diversos tipos de águas residuárias.

Matos et al. (2007) e Chagas et al. (2009) ao determinarem a melhor combinação concentração$\mathrm{pH}$ de coagulantes, de forma a maximizar a remoção de sólidos em suspensão presentes na água em recirculação do descascamento/despolpamento dos frutos do cafeeiro e na água residuária de laticínios, respectivamente, concluíram que o extrato de sementes de moringa mostrou grande potencial de utilização como coagulante natural e alternativo no tratamento das águas residuárias em estudo. Silva et al. (2001) estudaram a utilização de coagulantes naturais no tratamento de efluentes da indústria têxtil e observaram que, comparativamente aos coagulantes químicos utilizados, a moringa foi uma alternativa promissora no tratamento físicoquímico dessas águas residuárias, podendo ser empregada como auxiliar no tratamento primário, já que proporciona aumento na eficiência dos decantadores na remoção de sólidos em suspensão. Abdulsalam et al. (2007) ao utilizarem o extrato de sementes de moringa na clarificação de águas brutas de Maiduguri, Nigéria, observaram que a moringa pode substituir o sulfato de alumínio por proporcionar uma favorável razão custo-eficácia e baixa agressão ao meio ambiente.

Pesquisas têm sugerido, porém, que a adição de um sal no preparo de extrato de moringa pode proporcionar maior eficiência, da referida suspensão, na coagulação de sólidos em suspensão em águas residuárias (OKUDA et al., 1999; OKUDA et al., 2001).

Objetivou-se, com a realização do presente trabalho, avaliar o efeito da adição de substâncias químicas no preparo do extrato de sementes de moringa, quando utilizado na remoção de turbidez da água residuária de suinocultura (ARS). 


\section{MATERIAL E MÉTODOS}

O experimento foi realizado no Laboratório de Solo e Resíduos Sólidos do Departamento de Engenharia Agrícola da Universidade Federal de Viçosa (UFV).

A água residuária utilizada nos ensaios foi coletada na suinocultura da UFV, proveniente da lavagem das baias, entretanto, por ser o sistema de limpeza constituído por raspagem prévia do material sólido, a turbidez apresentada foi de apenas 56,4 UNT.

Foram utilizados o cloreto de sódio, $\mathrm{NaCl}$, e o hidróxido de cálcio, $\mathrm{Ca}(\mathrm{OH})_{2}$, sendo que para cada um deles, realizou-se três tratamentos. No primeiro, foi adicionado à ARS apenas o extrato de sementes de moringa (Moringa oleifera) numa concentração de sementes de $10 \mathrm{~g} \mathrm{~L}^{-1}$; no segundo, apenas solução de $\mathrm{NaCl}$ ou $\mathrm{Ca}(\mathrm{OH})_{2}$ de $1 \mathrm{~mol} \mathrm{~L}^{-1}$ e no terceiro, o extrato de moringa $\left(10 \mathrm{~g} \mathrm{~L}^{-1}\right)$ preparado com $\mathrm{NaCl}$ ou $\mathrm{Ca}(\mathrm{OH})_{2}$, ambos com $1 \mathrm{~mol} \mathrm{~L}^{-1}$.

$\mathrm{O}$ extrato de sementes de moringa foi obtido com a trituração, em liquidificador, de $1 \mathrm{~g}$ de sementes em $100 \mathrm{~mL}$ de água destilada, sendo a suspensão, posteriormente, filtrada em malha de $1 \mathrm{~mm}$. A solução preparada foi armazenada em geladeira (4 ${ }^{\circ} \mathrm{C}$ ) e utilizada no dia seguinte do seu preparo. No tratamento do extrato de sementes de moringa junto com a solução $\mathrm{NaCl}$, preparou-se $5 \mathrm{~g}$ de sementes de moringa em $500 \mathrm{~mL}$ de $\mathrm{NaCl} 1 \mathrm{~mol} \mathrm{~L}^{-1}$.

De cada tratamento, foram retiradas alíquotas de 2, 4, 8, 16 e $32 \mathrm{~mL}$ e aplicadas em $500 \mathrm{~mL}$ de ARS. Em seguida, as suspensões foram misturadas nos béqueres e colocadas em agitação no aparelho "Jar-test", permanecendo por 30 segundos sob agitação a $160 \mathrm{rpm}$ e, posteriormente, por 15 minutos, sob agitação a $15 \mathrm{rpm}$. As suspensões foram mantidas por períodos de 2 horas em repouso para a sedimentação do material nos béqueres. Decorrido o período, amostras do sobrenadante foram retiradas dos béqueres para medição da turbidez, medida em turbidímetro, modelo AP 2000.

Em todos os tratamentos foram realizadas três repetições e, por meio de regressão, foi feito o ajuste de equações matemáticas relacionando a média dos valores de turbidez como função das diferentes concentrações das soluções analisadas. Foi considerado satisfatório o ajuste que proporcionasse coeficiente de determinação maior que $70 \%$ e apresentasse significância mínima de $10 \%$ de probabilidade nos coeficientes. Para realizar a análise de regressão, utilizou-se o programa Sigma Plot 9.0.

\section{RESULTADOS E DISCUSSÃO}

Na Figura 1 está apresentado o gráfico contendo a média dos valores de turbidez como função das alíquotas adicionadas à ARS, quando tratada com extrato de sementes de moringa, solução de $\mathrm{NaCl} 1 \mathrm{~mol} \mathrm{~L}^{-1}$ e extrato de sementes de moringa preparadas em solução de $\mathrm{NaCl} 1 \mathrm{~mol} \mathrm{~L}^{-1}$.

De acordo com os resultados apresentados na Figura 1, pode-se observar que nenhum dos tratamentos proporcionou remoção da turbidez da ARS, uma vez que todos os valores medidos na água residuária tratada apresentaram-se maiores que os medidos na água residuária bruta. Verificase que houve aumento na turbidez, mesmo quando se aplicou apenas solução de $\mathrm{NaCl}$. Acredita-se que isso aconteceu devido à maior solubilização e a dispersão do material em suspensão. No caso da utilização de extrato de sementes de moringa, o aumento na turbidez se deveu ao material orgânico da própria semente de moringa.

Os resultados obtidos contrariam o que foi obtido por Okuda et al. (1999) que, ao avaliarem a turbidez residual de água sintética preparada com caulim utilizando a moringa extraída com água destilada e moringa extraída com $\mathrm{NaCl}$, concluíram que a moringa extraída com $\mathrm{NaCl}$ teve melhor atividade de coagulação, com dosagens de 7,4 vezes menores do que utilizando a moringa extraída em água destilada para redução da turbidez. Trabalhando com as mesmas concentrações utilizadas neste experimento, ou seja, $5 \mathrm{~g}$ de sementes em $500 \mathrm{~mL}$ de água residuária, os autores conseguiram baixar a turbidez de 35 UNT para 11,8 UNT, utilizando a dosagem ótima de $32 \mathrm{~mL}$ (equivalente a alíquota de $16 \mathrm{~mL}$, utilizada neste trabalho), quando o extrato de semente foi preparado com água destilada. Utilizando o extrato preparado em solução de $\mathrm{NaCl}$, a turbidez baixou para 1,6 UNT, numa dosagem ótima de $16 \mathrm{~mL}$ (equivalente a alíquota de $8 \mathrm{~mL}$ utilizada neste trabalho). 


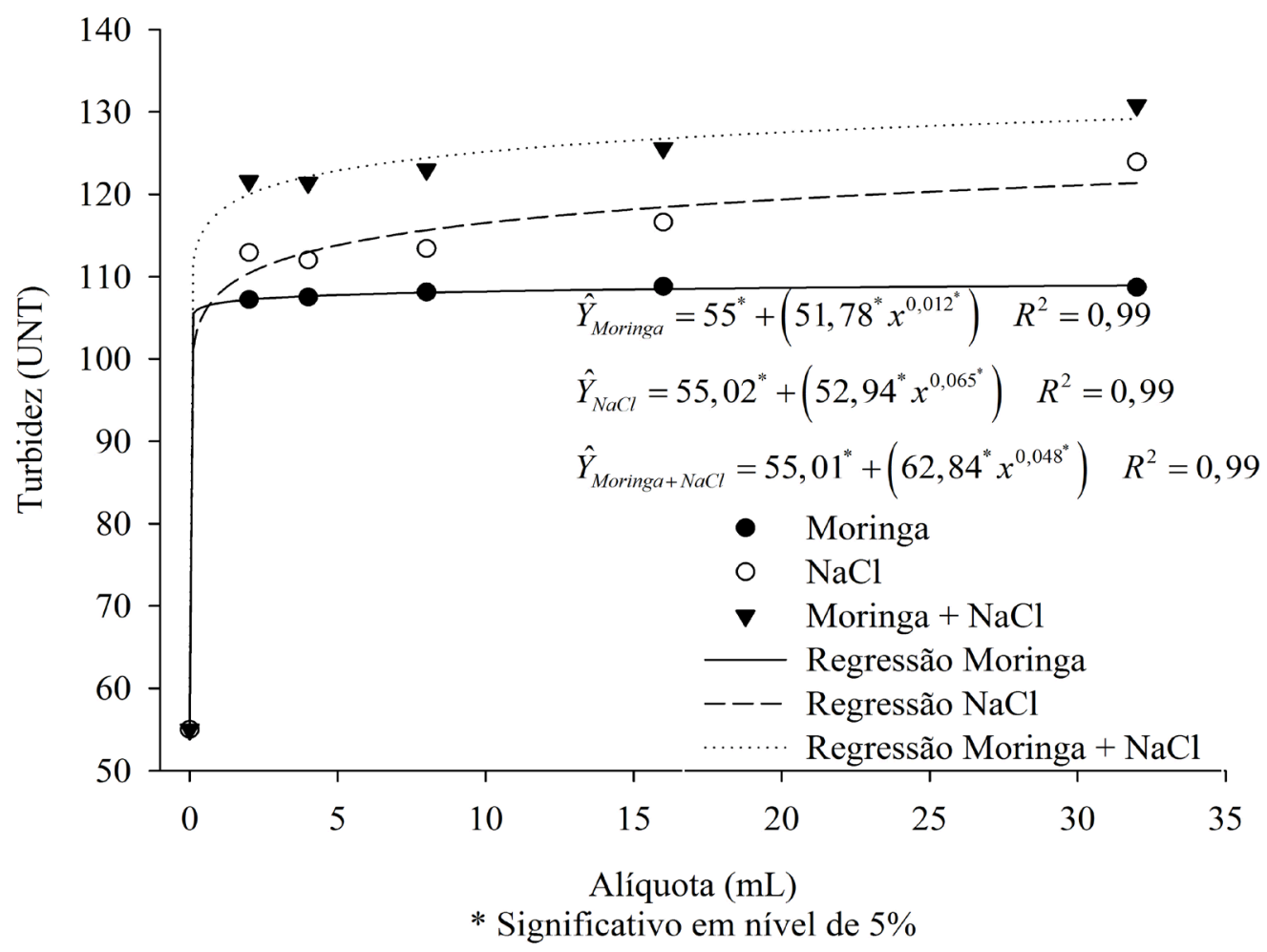

Figura 1. Média dos valores de turbidez em função das alíquotas adicionadas à água residuária da suinocultura quando tratada com extrato de sementes de moringa, solução de $\mathrm{NaCl} 1 \mathrm{~mol} \mathrm{~L}^{-1} \mathrm{e}$ extrato de sementes de moringa preparadas em solução de $\mathrm{NaCl} 1 \mathrm{~mol} \mathrm{~L}^{-1}$.

Acredita-se que, uma das possibilidades seja o fato de que o extrato produzido com sementes de moringa de diferentes regiões geográficas possua propriedades coagulantes diferentes (KATAYON et al., 2006). Segundo Narasiah et al. (2002) sementes de moringa de diferentes fontes podem apresentar diferentes desempenhos na coagulação devido a diferentes concentrações de proteínas e desenvolvimento das sementes.

Por outro lado, Lo Monaco et al. (2010) ao avaliarem a eficiência de diferentes concentrações do extrato de sementes de moringa como coagulante no tratamento de ARS, observaram que além da moringa não ter contribuído no processo de coagulação da ARS, a matéria orgânica originária das sementes contribuiu para o aumento de sólidos em suspensão na água. Desta forma, não foi possível apresentar um modelo que descrevesse o comportamento da turbidez em função das concentrações de sementes de moringa. Os autores suspeitaram haver menor eficiência do extrato de sementes de moringa quando o material em suspensão é, predominantemente, orgânico ou quando os solutos presentes nessa água interferem de forma negativa na coagulação desse material. Quando os autores utilizaram o extrato de sementes de moringa no tratamento de esgoto doméstico, cuja concentração de matéria orgânica é sabidamente menor que a da água residuária de suinocultura, obtiveram remoção de $22,4 \%$ da turbidez. Ao avaliarem a eficiência do extrato de sementes de moringa no tratamento de água de abastecimento, caracterizada como uma água rica em material inorgânico mas com baixa concentração de material orgânico, os mesmos autores obtiveram uma remoção de $98 \%$, numa concentração de $0,4 \mathrm{~g} \mathrm{~L}^{-1}$ de sementes de moringa.

Uma vez que, Okuda et al. (1999) ao utilizarem as mesmas concentrações utilizadas nesse trabalho obtiveram bons resultados no tratamento de outro tipo de água, outra possibilidade seria o fato de que o extrato de 
sementes de moringa, mesmo quando preparados em solução de $\mathrm{NaCl}$, não é eficaz na remoção da turbidez de águas residuárias ricas em material orgânico, como as de suinocultura. Nesse caso, suspeita-se que a baixa remoção da turbidez pela moringa possa estar relacionada com a quantidade de ácidos fúlvicos presentes na água residuária de suinocultura. Campos et al. (2005) ao estudarem a influência das características das substâncias húmicas na eficiência de coagulação com o sulfato de alumínio, observaram que quanto maior a porcentagem de ácidos fúlvicos presente nas frações de substâncias húmicas de diferentes massas molares na água, maior foi a dificuldade de sua remoção, ou seja, maior foi a dosagem de coagulante exigida para se obter melhores resultados de remoção. Além disso, a forma como a ARS tem sido gerada (raspagem prévia dos dejetos sólidos antes das limpezas das baias) possa, também, ter influenciado nos resultados obtidos, tendo em vista que a ARS utilizada apresentava alta concentração de sólidos dissolvidos e baixa concentração de sólidos em suspensão, o que pode ser comprovado pela relativamente baixa turbidez medida.

$\mathrm{Na}$ Figura 2 está apresentado o gráfico contendo a média dos valores de turbidez como função das alíquotas adicionadas à ARS, quando tratada com extrato de sementes de moringa, solução de $\mathrm{Ca}(\mathrm{OH})_{2} 1 \mathrm{~mol} \mathrm{~L}^{-1} \mathrm{e}$ extrato de sementes de moringa preparadas em solução de $\mathrm{Ca}(\mathrm{OH})_{2} 1 \mathrm{~mol} \mathrm{~L}^{-1}$.

De acordo com os resultados apresentados na Figura 2, pode-se observar que o tratamento utilizando apenas o extrato de sementes de moringa não proporcionou remoção satisfatória da turbidez da ARS, tal como observado no experimento utilizando o $\mathrm{NaCl}$. Em todas as alíquotas utilizadas, os valores de turbidez permaneceram próximos ao valor afluente (55 UNT). Acredita-se, que isso se deveu ao material orgânico da própria semente de moringa tal como explicado anteriormente, fundamentando-se no trabalho de Campos et al. (2005).

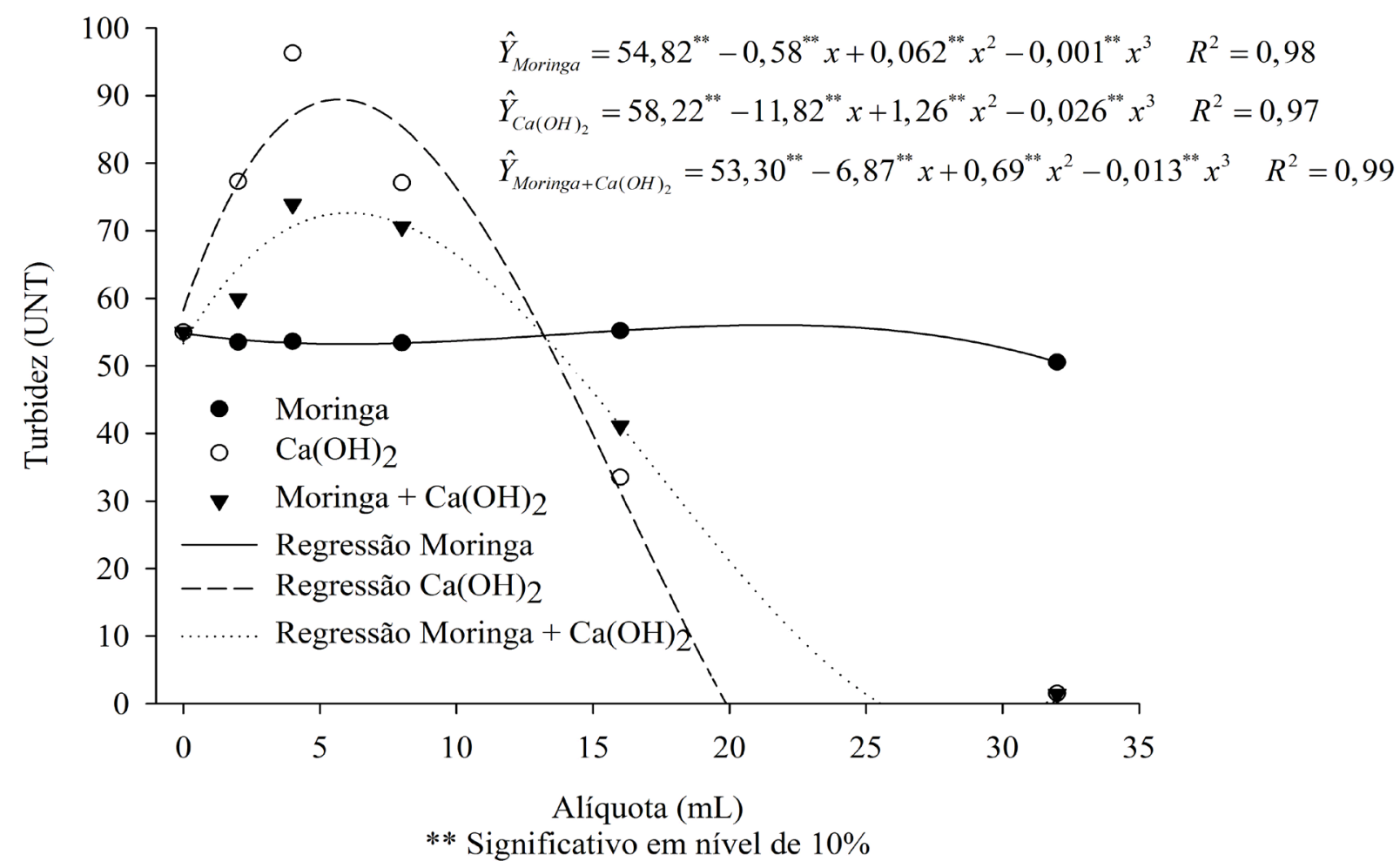

Figura 2. Média dos valores de turbidez em função das alíquotas adicionadas à água residuária da suinocultura quando tratada com extrato de sementes de moringa, solução de $\mathrm{Ca}(\mathrm{OH})_{2} 1 \mathrm{~mol} \mathrm{~L}^{-1}$ e extrato de sementes de moringa preparadas em solução de $\mathrm{Ca}(\mathrm{OH})_{2} 1 \mathrm{~mol} \mathrm{~L}^{-1}$. 
Nos outros dois tratamentos (solução salina e extrato de sementes de moringa preparado em solução salina), somente a partir da alíquota de 16 $\mathrm{mL}$ é que houve redução satisfatória de turbidez da ARS. A alíquota de $32 \mathrm{~mL}$ proporcionou remoções de 97,4 e $97,5 \%$ da turbidez inicial, nos tratamentos em que foi adicionada a solução de $\mathrm{Ca}(\mathrm{OH})_{2}\left(0,64 \mathrm{~g} \mathrm{~L}^{-1}\right)$ e o extrato de sementes de moringa preparado em solução de $\mathrm{Ca}(\mathrm{OH})_{2}$ $\left(0,64 \mathrm{~g} \mathrm{~L}^{-1}\right.$ de cal $+0,64 \mathrm{~g} \mathrm{~L}^{-1}$ de sementes de moringa), respectivamente, revelando assim, nenhuma diferença entre esses dois tratamentos. Dessa forma, pode-se concluir que a elevada eficiência de remoção nesses dois tratamentos se deveu à presença do $\mathrm{Ca}(\mathrm{OH})_{2}$, já que no tratamento em que a ARS recebeu somente as alíquotas de extrato de sementes de moringa não houve significativa remoção de turbidez. Isso decorre do fato de que a cal hidratada, $\mathrm{Ca}(\mathrm{OH})_{2}$, tem reconhecida ação coagulante (MATOS et al., 2007b).

Os resultados obtidos indicaram ação eficaz da cal hidratada na remoção da turbidez da ARS, porém não se pode dizer o mesmo do extrato de sementes de moringa, sabidamente eficiente na remoção de sólidos inorgânicos em suspensão.

Por esta razão, necessita-se da condução de mais pesquisas para melhor entendimento da razão da menor eficiência do extrato de sementes de moringa, preparado ou não em solução salina, na remoção da turbidez de água residuária da suinocultura.

\section{CONCLUSÃO}

- De acordo com os resultados obtidos, pode-se concluir que:A adição de extrato de sementes de moringa, preparados em água destilada ou solução $\mathrm{NaCl} 1 \mathrm{~mol} \mathrm{~L}^{-1}$, não proporcionou remoção da turbidez da água residuária da suinocultura; e

- Praticamente não houve diferença na remoção de turbidez da ARS entre os tratamentos que receberam o extrato de sementes de moringa e o extrato de sementes de moringa preparado em solução de $\mathrm{Ca}(\mathrm{OH})_{2}$. As maiores remoções de turbidez da ARS foram obtidas utilizandose a alíquota de $32 \mathrm{~mL}$, tanto de solução $\mathrm{Ca}(\mathrm{OH})_{2}$ como de extrato de sementes de moringa preparado em solução $\mathrm{Ca}(\mathrm{OH})_{2}$, proporcionando, respectivamente, remoções de 97,4 e $97,5 \%$ da turbidez inicial.

\section{REFERÊNCIAS BIBLIOGRÁFICAS}

ABDUlSAlAM, S.; GITAL, A.A.; MISAU, I.M.; SULEIMAN, M.S. Water clarification using Moring oleifera seed coagulant: Maiduguri raw water as a case study. Journal of Food, Agriculture \& Environment, Helsinki, v.5, n.1, p.302-306, 2007.

BHATIA, S.; OTHMAN, Z.; AHMAD, A.L. Pretreatment of palm oil mill effluent (POME) using Moringa oleifera seeds as natural coagulant. Journal of Hazardous Materials, Amsterdam, v.145, n.1, p.120-126, 2007.

CAMPOS, S.X.; BERNARDO, L.D.; VIEIRA, E.M. Influência das características das substâncias húmicas na eficiência da coagulação com sulfato de alumínio. Engenharia Sanitária e Ambiental, Rio de Janeiro, vol.10, n.3, p.194-199, jul/set. 2005.

CHAGAS, R.C.; SARAIVA, C.B.; MOREIRA, D.A.; SILVA, D.J.P.; MATOS, A.T.; FARAGE, J.A. Uso do extrato de moringa como agente coagulante no tratamento de águas residuárias de laticínios. In: XXVI CONGRESSO NACIONAL DE LATICÍNIOS, 2009, Juiz de Fora, MG). Anais... Juiz de Fora: ICLT/EPAMIG, 2009.

DAL BOSCO, T.C.; SAMPAIO, S.C.; OPAZO, M.A.U.; GOMES, S.D.; NÓBREGA, L.H.P. Aplicação de água residuária de suinocultura em solo cultivado com soja: cobre e zinco no material escoado e no solo. Engenharia Agrícola, Jaboticabal, v.28, n.4, p.699-709, out/dez. 2008.

HEREDIA, J.B.; MARTÍN, J.S. Removal of sodium lauryl sulphate by coagulation/floculation with Moringa oleifera seed extract. Journal of Hazardous Materials, Amsterdam, v.164, n.2-3, p.713-719, may. 2009. 
HEREDIA, J.B.; MARTÍN, J.S.; REGALADO, A.D. Removal of carmine indigo dye with Moringa oleifera seed extract. Industrial and Engineering Chemistry Research, Columbus, v.48, n.14, p.6512-6520, 2009.

KATAYON, S.; Ng, S.C; JOHARI, M.; GHANI, L. Preservation of coagulation efficiency of Moringa oleifera, a natural coagulant. Biotechnology and Bioprocess Engineering, Seoul, v.11, n.6, p.489495, 2006.

LO MONACO, P.A.V.; MATOS, A.T.; RIBEIRO, I.C.A.; NASCIMENTO, F.S.; SARMENTO, A.P. Utilização de extrato de sementes de moringa como agente coagulante no tratamento de água para abastecimento e águas residuárias. Ambiágua, Taubaté, v.5, n.3, p.222-231, 2010.

LO MONACO, P.A.V.; MATOS, A.T.; SARMENTO, A.P.; LOPES JÚNIOR, A.V.; LIMA, J.T. Desempenho de filtros constituídos por fibras de coco no tratamento de águas residuárias de suinocultura. Engenharia na Agricultura, Viçosa, v.17, n.6, p.473-480, 2009.

MATOS, A.T.; CABANELLAS, C.F.G.; CECON, P.R.; BRASIL, M.S.; MUDADO, C.S. Efeito da concentração de coagulantes e do $\mathrm{pH}$ da solução na turbidez da água, em recirculação, utilizada no processamento dos frutos do cafeeiro. Engenharia Agrícola, Jaboticabal, v.27, n.2, p.544-551, 2007 a.

MATOS, A.T.; EUSTÁQUIO JÚNIOR, V.; PEREIRA, P.A.; MATOS, M.P. Tratamento da água para reuso no descascamento/despolpa dos frutos do cafeeiro. Engenharia na Agricultura, Viçosa, v.15, n.2, 173-178, $2007 \mathrm{~b}$.

MATOS, A.T.; MAGALHÃES, M.A.; FUKUNAGA, D.C. Remoção de sólidos em suspensão na água residuária da despolpa de frutos do cafeeiro em filtros constituídos por pergaminho de grãos de café submetido a compressões. Engenharia Agrícola, Jaboticabal, v.26, n.2, p.610-616, 2006.

MORAES, L.C.K. Estudo da coagulaçãoultrafiltração com o biopolímero quitosana para a produção de água potável. 2004. $135 \mathrm{f}$, Dissertação (Mestrado em Engenharia Química) Universidade Estadual de Maringá, Maringá, 2004.

MUYIBI, S.A.; EVISON, L.M. Optimizing physical parameters affeting coagulation of turbid water with Moringa oleifera seeds. Water Research, Oxford, v.29, n.12, p.2689-2695, dec. 1995.

NARASIAH, K.S.; VOGEL A.; KRAMADHATI, N.N. Coagulation of turbid waters using Moringa oleifera seeds from two distinct sources. Water Science Technology, Inglaterra, Water Supply, v.2, n.5-6, p.83-88, 2002.

OKUDA, T.; BAES, A.U.; NISHIJIMA, W.; OKADA, M. Coagulation mechanism of salt solution-extracted active component in moringa oleifera seeds. Water Research, Oxford, v.35, n.3, p.830-834, 2001.

OKUDA, T.; BAES, A.U.; NISHIJIMA, W.; OKADA, M. Improvement of extraction method of coagulation active components from moringa oleifera seed. Water Research, Oxford, v.33, n.15, p.3373-3378, 1999.

SILVA, F.J.A.; SILVEIRA NETO, J.W.; MOTA, F.S.B.; SANTOS, G.P. Descolorização de efluente da indústria têxtil utilizando coagulante natural (Moringa oleifera e quitosana). In: CONGRESSO BRASILEIRO DE ENGENHARIA SANITÁRIA E AMBIENTAL, 21, 2001, João Pessoa. Anais... João Pessoa: ABES, 2001. CD-ROM.

SILVA, M.E.R.; AQUINO, M.D.; SANTOS, A.B. Pós-tratamento de efluentes provenientes de reatores anaeróbios tratando esgotos sanitários por coagulantes naturais e nãonaturais. Revista Tecnologia, Fortaleza, v.28, n.2, p.178-190, dez. 2007. 